\title{
ACOMPANHAMENTO DO TREINAMENTO DOS FAMILIARES PARA O MANEJO DO USO DE NUTRIÇÃO PARENTERAL DOMICILIAR: RELATO DE EXPERIÊNCIA
}

\author{
Felipe Leonardo Rigo \\ Hospital Infantil João Paulo II \\ felipeleonardorigo@hotmail.com \\ Caroline Soares Rodrigues \\ Hospital Infantil João Paulo II \\ carolrodriguespaes@gmail.com \\ Cassidy Tavares Silva \\ Hospital Infantil João Paulo II \\ Fundação Hospitalar do Estado de Minas Gerais \\ tavarescassidy@gmail.com \\ Mércia Beatriz Martins Silva \\ Hospital Infantil João Paulo II \\ merciabiaII@gmail.com
}

\section{RESUMO}

INTRODUÇÃO: A Terapia Nutricional (TN) constitui procedimentos terapêuticos para manutenção ou recuperação do estado nutricional do indivíduo por meio da nutrição enteral e parenteral. Os avanços na terapia nutricional pediátrica e o surgimento de estratégias para sua organização e qualificação possibilitou que o seu manejo ultrapassasse o âmbito hospitalar e é crescente os programas que possibilitam esse cuidado em domićlio. A desospitalização permite a continuidade do atendimento, a humanização dos cuidados e maior comodidade para os sujeitos envolvidos. Ainda contribui para a reintegração social, reduz o risco de infecção e os custos hospitalares. OBJETIVO: Descrever o treinamento realizado pelos enfermeiros aos familiares de crianças em uso nutrição parenteral (NP) durante a internação hospitalar. METODOLOGIA: Trata-se um relato de experiência pela vivências das residentes de enfermagem do programa de urgência e emergência na unidade de cuidados paliativos de um hospital pediátrico localizado em Belo Horizonte. RESULTADOS: A capacitação dos familiares cuidadores, inicia-se com a entrega de um instrumento elaborado em parceria com as residentes de enfermagem, no qual traz o passo a passo de todas as etapas do manejo da NP. Posteriormente, os cuidadores observam os profissionais realizaram todo o manejo da NP desde a dispensa na farmácia até a administração na criança. Em seguida, os cuidadores começam paulatinamente a realizar a assistência (preparo, instalação da NP, heparinazação e troca de curativo do cateter central). O treinamento teórico-prático dos familiares é finalizado após avaliação formal dos enfermeiros quanto às suas habilidades para realizar todos os procedimentos. CONCLUSÃO: A capacitação de familiares com orientações assertivas é fundamental para a segurança dos cuidados ao paciente na continuidade da assistência em domić́lio.

PALAVRAS-CHAVE: Capacitação. Nutrição Parenteral. Enfermagem pediátrica 